\title{
Endothelial dysfunction: role in obesity-related disorders and the early origins of CVD
}

\author{
Atul Singhal \\ MRC Childhood Nutrition Research Centre, Institute of Child Health, 30 Guilford Street, London WCIN 1EH, UK
}

\begin{abstract}
Atherosclerotic CVD is the most common cause of death in the West. Yet, its pathogenesis and early development are only partially understood. Central to the early atherosclerotic process is impairment of vascular endothelial function. Endothelial dysfunction can be measured noninvasively and is evident in children before clinical manifestations of atherosclerosis in adulthood. Factors in early life, such as conventional cardiovascular risk factors, or programming by perinatal growth and nutrition strongly affect endothelial function and hence the development of atherosclerosis and CVD. For instance, low birth weight and faster growth early in infancy have a detrimental effect on vascular structure and function. Childhood obesity, a key independent risk factor for CVD, also adversely affects early vascular health. Obesity is associated with endothelial dysfunction and greater arterial stiffness from as early as the first decade of life, while weight loss is beneficial. This effect on vascular function is probably mediated in part by low-grade inflammation and insulin resistance associated with obesity or by the production by adipose tissue of cytokine-like molecules, collectively termed adipokines. A high leptin concentration, in particular, is found in obese individuals and is strongly associated with vascular changes related to early atherosclerosis. The present review focuses on the early origins of endothelial dysfunction, emphasising the role of obesity. It also considers the mechanisms by which obesity impairs endothelial function, understanding of which will be important to further scientific knowledge and to improve public health.
\end{abstract}

Endothelial dysfunction: Role of obesity: Early origins of CVD

With a one in two lifetime risk at the age of 40 years, atherosclerotic CVD is the most important cause of death in Western populations (Lloyd-Jones et al. 1999). Yet, despite great progress in its prevention and management much remains unknown about its pathogenesis and early development.

Indeed, despite extensive epidemiological research standard risk factors such as obesity, smoking, high blood pressure and family history identify only $60 \%$ of the men at risk of myocardial infarction (Shaper et al. 1986). In fact, most deaths from CHD occur in men classified as at low risk by the Framingham equations (Brindle et al. 2003). Consequently, in the last 20 years there has been a major research investment into the lifestyle and environmental factors that might explain cardiac events in individuals considered by conventional methods to be at low risk.

It is now known that factors which act early in life have a major impact on the development of atherosclerosis and lifetime risk of CVD. Atherosclerosis has been shown to have a long preclinical phase, with development of pathological changes in arteries of children and young adults well before clinical manifestations of the disease in adults (Stary, 1989). Factors that act in fetal life ('the fetal origins of CVD hypothesis'; Barker et al. 1993) and the early postnatal period (Singhal \& Lucas, 2004) influence, or programme (Lucas, 1991), the development of atherosclerosis and its complications. This programming might occur directly via an effect on vascular physiology (Leeson et al. 1997, 2000) and also via the programming of cardiovascular risk factors such as obesity (Singhal et al. 2002 b). Conventional cardiac risk factors that act in childhood might be particularly detrimental (Klag et al. 1993). For instance, obesity in childhood has adverse effects on adult cardiovascular health that are independent of adult weight (Must et al. 1992; Vanhala et al. 1998).

The ability to detect non-invasively the earliest physiological changes in the vascular biology of atherosclerosis has transformed the understanding of early cardiovascular 
risk factors. Although the development of atherosclerosis is a complex interaction between endothelial cells, platelets, inflammation and dyslipidaemia, a key early stage in this process is impairment of endothelial cell function. Thus, measurement of endothelial dysfunction using high-resolution vascular ultrasound allows investigation of the early origins of CVD without the need to follow individuals to an age when clinical manifestations of atherosclerosis become apparent. These techniques suggest that programming effects and classical cardiovascular risk factors such as obesity impair endothelial function from as early as the first decade of life (Leeson et al. 1997). The present review focuses on the early origins of endothelial dysfunction, emphasising the role of obesity and the mechanisms by which adiposity impairs vascular health.

\section{Endothelial dysfunction is central to the development of atherosclerosis}

Furchgott \& Zawadzki (1980) were the first to identify the central role of the endothelium, the cellular monolayer that lines the vasculature, in arterial physiology. They discovered that the production of a relaxing factor (endothelium-derived relaxing factor) is essential for the vasodilator action of acetylcholine in isolated arterial strips. Subsequently, endothelium-derived relaxing factor was characterised by Moncada and colleagues (Palmer et al. 1987) as NO. It is now known that endothelialderived NO is an important anti-atherogenic molecule that not only has vasodilator actions, but also inhibits platelet activation, monocyte-endothelium interactions and smooth muscle cell proliferation and migration. Thus, a reduction in NO bioavailability, both by a decrease in production or by its inactivation, e.g. by reactive oxygen species, is a measure of the health of the endothelium and directly facilitates the development of atherosclerosis.

Indeed, the pivotal role of the vascular endothelium in the pathogenesis and progression of atherosclerosis is now well established (Ross, 1993). These cells are important in the regulation of vasomotion, thrombosis and inflammation. Consequently, impaired endothelial function is an early stage in the atherosclerotic process and can be detected before the development of angiographicallyimportant atherosclerotic plaques in both coronary and peripheral vessels. In fact, there is a spatial relationship between endothelial function and sites of atheroma (Anderson et al. 1995). Furthermore, endothelial dysfunction in peripheral arteries correlates closely with endothelial dysfunction in the coronary arteries, shows a 'dose-response' relationship with classical cardiovascular risk factors and improves with pharmacological therapies and lifestyle interventions that aim to reduce cardiac risk (Mullen et al. 1997). Importantly, endothelial dysfunction is not simply a marker of early vascular disease but a measure of the primary vascular injury that initiates the process of atherosclerosis (Mullen et al. 1997).

Endothelial dysfunction is also directly related to clinical outcomes (Kuvin \& Karas, 2003). Coronary events are markedly more common in men with or without mild coronary artery disease who have impaired coronary endothelial function. Impaired brachial artery endothelial function independently predicts both post-operative outcomes in high-risk patients undergoing peripheral vascular surgery and, in older individuals, clinical cardiovascular events. Endothelial function, therefore, appears to be of prognostic value independent of traditional cardiovascular risk factors.

\section{Measurement of endothelial function}

The function of the endothelium is usually assessed in either the coronary or peripheral circulation. Coronaryartery endothelial function is most commonly determined by the intra-coronary infusion of acetlycholine, which causes release of NO and hence coronary artery vasodilation. In the peripheral circulation the brachial artery is the most frequent site although carotid, superficial femoral and radial arteries have also been used. Brachial artery endothelium function is usually measured non-invasively by flow-mediated endothelial-dependent vasodilation (FMD). Typically, ischaemia is induced in the forearm or hand using a tourniquet inflated to above systolic pressure. Release of the tourniquet causes reactive hyperaemia, an increase in blood flow through the brachial artery, and hence a release of NO. The resulting vasodilation is measured by continuous high-resolution ultrasound and the maximum vasodilation is expressed as a percentage of the baseline brachial arterial diameter (Leeson et al. 1997). Maximal FMD shows quite wide variability even in healthy young subjects, but correlates closely with endothelial NO bioavailability. In experienced hands the technique demonstrates excellent reproducibility (Sorensen et al. 1995), while the portability of the equipment allows large-scale national epidemiological studies in large numbers of participants.

Other measures of the function and integrity of the endothelium include various biochemical markers. For instance, concentrations of cellular adhesion molecules, which play a key role in leucocyte adherence, are elevated in patients with atherosclerosis and may predict cardiovascular risk (Parker et al. 2001).

\section{Arterial distensibility}

Another key measure of early atherosclerosis is the stiffness or elasticity of the arterial wall. Arterial stiffness (or compliance) is determined by arterial transmural pressure and its structural components of mainly collagen and elastin. Like endothelial function, arterial stiffness can be measured, non-invasively, using high-resolution ultrasound and is determined, in part, by basal endothelial NO production, which suggests a common mechanism for the vascular changes associated with early atherosclerosis (Wilkinson et al. 2002). Furthermore, arterial stiffness correlates closely with the extent of atherosclerotic disease (Hirai et al. 1989), with cardiovascular risk factors (even from a young age; Tounian et al. 2001) and with cardiovascular risk (Blacher et al. 1999).

Arterial stiffness is usually estimated from the arterial distensibility, which is measured as the change in arterial diameter of a peripheral artery caused by the pulse pressure (Lehmann et al. 1997). Systolic blood pressure 
minus diastolic blood pressure obtained from the same limb provides a proxy for the pulse pressure at the crosssection of the blood vessel being studied. A smaller change in arterial diameter per $\mathrm{mm} \mathrm{Hg}$ pulse pressure indicates a stiffer artery.

Alternatively, arterial stiffness is estimated indirectly from the pulse wave velocity, i.e. the time it takes the pulse wave to travel a given distance along the vasculature. Pulse wave velocity is increased in stiffer arteries and can be measured in the peripheral and central circulation using techniques such as Doppler ultrasound and magnetic resonance imaging (Lehmann et al. 1997). These methods depend on both the precise measurement of transit time and the path length.

Collectively, therefore, measures of vascular function such as FMD and arterial distensibility provide unique tools for the investigation, non-invasively, of the early origins of CVD. These measures are closely associated with cardiovascular risk factors and, at least in older individuals, show some prognostic value. Moreover, unlike other cardiovascular outcomes, these techniques can be used to measure the earliest stages of the atherosclerotic process in children, thereby avoiding some of the confounding effects of risk factors later in life on programming of adult coronary artery disease. Finally, early vascular dysfunction provides a potential mechanism that links factors in early life with later CVD.

\section{Endothelial function and the programming of adult CVD}

Over the last 20 years, the idea that nutrition and growth in early life contribute to the risk of adult CVD and its risk factors has been a major focus for research. However, despite a substantial research investment in the field, most previous data have been observational and retrospective. More recently, the application of non-invasive techniques to detect the early stages of atherosclerosis in children and young adults has allowed prospective studies and helped elucidate the mechanisms involved.

\section{Historical overview}

The first evidence for critical windows in development was that of early 'imprinting' behaviour of birds, which was initially published in 1873 (Spalding, 1954). Then, in the 1960s McCance (1962) showed that nutrition could act during such windows to programme later biology. He showed that rats raised in small litters, and therefore overfed early in postnatal life, are programmed for greater body size as adults. Subsequently, rats overfed in the brief suckling period have been shown to have higher plasma insulin and cholesterol concentrations (Hahn, 1984), while early nutrition in baboons has been found to have a major impact on later obesity (Lewis et al. 1986) and atherosclerosis (Lewis et al. 1988).

The concept that factors early in life affect long-term health has been confirmed extensively in man. Barker and others (Barker et al. 1993; Frankel et al. 1996) have shown that low birth weight and weight at age 1 year is associated with a greater risk of later CVD (Barker et al. 1993), particularly in those individuals who become obese (Frankel et al. 1996) or show catch-up growth in childhood. Interpreted as an adverse long-term effect of poor fetal nutrition and growth in infancy (the 'fetal origins of adult disease hypothesis'; Barker et al. 1993), these studies have led to calls for public health policies that promote fetal or maternal nutrition and infant growth.

Nevertheless, despite extensive epidemiological research, a causal role for fetal nutrition or growth in programming long-term health has not been established. 'Catch-up growth' in infancy has been postulated to explain associations between low birth weight-for-gestational age and later cardiovascular risk factors (Cianfarani et al. 1999). Other explanations have included the selective survival in infancy of those predisposed to later disease, or the influence of genes on both low birth weight and later cardiovascular risk factors. Most explanations, however, have emphasised a central role for intrauterine growth retardation. For instance, for the programming of insulin resistance, as reviewed recently (Cianfarani et al. 1999), these explanations have included the 'thrifty phenotype' hypothesis, 'fetal salvage' model and an effect of early 'catch-up growth' on later insulin-like growth factor 1 concentration.

These earlier studies have raised a common hypothesis, that programming of atherosclerosis in adults by suboptimal fetal nutrition (Martyn et al. 1998) predisposes to coronary artery disease. However, interpretation of these earlier reports has been limited by their retrospective design. Recent prospective data suggest that programming effects are seen much earlier in the atherosclerotic process. For instance, low birth weight correlates with endothelial dysfunction measured by biochemical techniques (McAllister et al. 1999) and by FMD (Leeson et al. 1997, 2001) or acetylcholine-induced vasodilation (Norman \& Martin, 2003). Small size at birth is also associated with preclinical atherosclerotic changes such as greater intimamedia thickness (Lamont et al. 2000) and impaired arterial distensibility (Cheung et al. 2004). These effects are found even in young children (Leeson et al. 1997; Martin et al. 2000; Cheung et al. 2004) and are modified by classical cardiovascular risk factors in adulthood (Leeson et al. 2001) and by extreme prematurity (Norman \& Martin, 2003). The finding that vascular function is impaired in infants born small-for-gestational age, but not in those of low birth weight as a consequence of prematurity (Singhal et al. 2001b; Cheung et al. 2004), suggests that intrauterine growth retardation, rather than low birth weight itself, is important for vascular programming.

Whilst previous studies have been observational and have focused on low birth weight and fetal nutrition, an experimental approach has been used to investigate the impact of early postnatal nutrition on CVD. It has been found that preterm infants assigned randomly to human milk $v$. formula for an average of 4 weeks have marked benefits $>16$ years later for the major components of the metabolic syndrome (blood pressure, leptin 'resistance' suggestive of future obesity, insulin resistance and lipid profile; Singhal et al. 2001a, 2002c, 2003, 2004b). These observations have been confirmed in infants born at term and have generated a novel hypothesis to explain both the 
cardiovascular benefits of breast-feeding and the 'fetal origins of CVD'.

\section{The growth acceleration hypothesis}

As a unifying hypothesis, it has been suggested that the long-term benefits of breast-milk compared with formula are a consequence of relative undernutrition and slower growth in those breast-fed (Singhal \& Lucas, 2004). In support of this hypothesis, it has been found that a lower nutrient intake from either human milk or standard formula is beneficial for later insulin resistance compared with an enriched formula (Singhal et al. 2003). These findings are not confined to infants born prematurely. In an intervention study of infants born full-term but small-for-gestational age, it has been found that those randomly assigned to a standard formula for the first 9 months have a lower blood pressure 6-8 years later than those fed a nutrient-enriched formula that promoted growth (A Singhal, unpublished results). Further analysis has suggested that faster growth explains the adverse effects of a nutrient-enriched formula on later insulin resistance and blood pressure. Thus, these data raise the hypothesis that relative undernutrition and slower growth in infancy reduce risk factors for the development of atherosclerosis, CVD and non-insulin-dependent diabetes mellitus. Furthermore, because the growthretarded fetus is one category of individual that shows faster postnatal growth (while large newborns show growth deceleration) postnatal growth acceleration could also explain previous associations between low birth weight and later cardiovascular risk.

Consistent with this hypothesis, accelerated growth in the first 2 weeks of life, the period of fastest postnatal growth in man, is associated with greater endothelial dysfunction in adolescence (Singhal et al. 2004a; Fig. 1). The size of the effect is substantial. Adolescents born preterm with the greatest weight gain during this period have $4 \%$ lower FMD of the brachial artery than those with

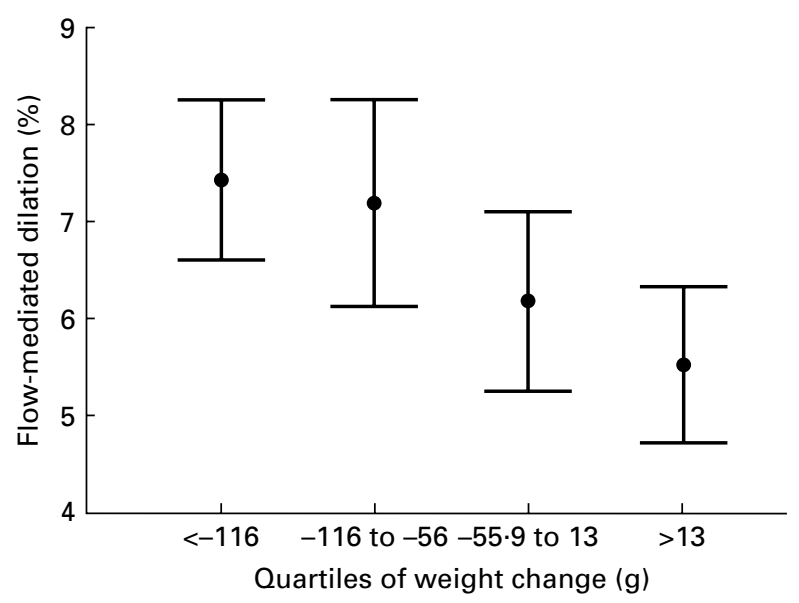

Fig. 1. Flow-mediated endothelial-dependent dilation in adolescence according to quartiles of weight change in the first two postnatal weeks. Values are means and $95 \% \mathrm{Cl}$ represented by vertical bars. Analysis was by linear regression. (Data from Singhal et al. 2004a.) the lowest weight gain, an effect similar to that of insulindependent diabetes mellitus (4\%; Clarkson et al. 1996) and smoking (6\%; Celermajer et al. 1993) in adults. Interestingly, the effects of faster early postnatal growth are independent of size at birth as measured by the $\mathrm{z}$ score for birth weight (Singhal et al. 2004a). Similar adverse effects of faster growth are seen for later insulin resistance (Singhal et al. 2003), while others have shown previously that faster growth in infancy is associated with greater risk of obesity later in life (Stettler et al. 2002).

In summary, a nutrient-enriched early diet and faster postnatal growth have a detrimental programming effect on long-term vascular function. Both preterm and full-term infants are programmed and the effects appear to be independent of size at birth. The size of the effect is large and so likely to have considerable implications for public health.

\section{Endothelial function and obesity}

Other than programming effects by perinatal factors, childhood is a second critical period for the early origins of CVD. Classical cardiovascular risk factors in children, e.g. high cholesterol concentration, are associated with preclinical atherosclerotic changes, such as lower arterial distensibility (Leeson et al. 2000). Childhood obesity, in particular, has a major adverse effect on later cardiovascular risk (Must et al. 1992; Vanhala et al. 1998).

Although obesity is a well-established independent risk factor for coronary artery disease, the mechanisms that relate fat mass to vascular health are poorly understood. Excess fat, and particularly visceral fat, predispose to the major components of the metabolic syndrome (blood pressure, insulin resistance, abnormal serum lipids and inflammation) that influence cardiac risk. Obesity might also promote preclinical atherosclerotic changes via a direct effect on vascular physiology.

Several reports now suggest that obesity impairs vascular function (Williams et al. 2002). Obese individuals show an impaired endothelial-mediated vasodilator response to increased blood flow (Arcaro et al. 1999), to insulin (Westerbacka et al. 1999) and to biochemical agents (Steinberg et al. 1996). Similarly, obesity is associated with greater arterial stiffness (Wildman et al. 2003) and, as expected, visceral adiposity is particularly detrimental (Resnick et al. 1997). In accord with a causal role for obesity in the pathogenesis of early atherosclerosis, weight loss improves both endothelial function (Ziccardi et al. 2002) and arterial stiffness (Yamashita et al. 1998). However, the effect of weight loss on vascular function is not consistent across studies. A recent report has suggested that there is no benefit on brachial artery FMD of a moderate extent of weight loss over 3 months (Brook et al. 2004). This discrepancy may be a result of factors such as differences in the site or techniques used to measure endothelial function, the diet that led to weight loss or the time over which weight loss was achieved. Nevertheless, these data raise the important question of the extent to which the effects of obesity on vascular stiffness are acute and therefore reversible. 
The precise mechanism by which obesity in childhood increases cardiovascular risk above that of fatness in adult life remains unexplained. One possibility is that a prolonged exposure of arteries to the metabolic milieu associated with obesity (such as a high insulin concentration; Vanhala et al. 1998) impairs endothelial function. Evidence of endothelial dysfunction (Tounian et al. 2001) and increased arterial stiffness (Wildman et al. 2003) in young individuals who are obese is, therefore, of particular concern in view of the present epidemic of childhood obesity.

\section{Mechanisms}

While there is now strong evidence that obesity impairs vascular function from an early age, the underlying mechanism for this effect is contentious. Obese individuals more commonly show features of the metabolic syndrome, the clustering of phenotypes associated with increased cardiovascular risk. Insulin resistance is suggested to be central to the pathogenesis of this syndrome and to explain associations between obesity and vascular dysfunction. However, recent additions to this clustering, such as an elevation of levels of plasminogen-activator inhibitor, microalbuminaria and endothelial dysfunction cannot be easily explained by insulin-mediated mechanisms. As obesity is associated with features of acute-phase activation and low-grade inflammation, elevated levels of inflammatory markers such as fibrinogen, C-reactive protein and IL-6 might also affect vascular dysfunction. Furthermore, adipose tissue produces cytokine-like molecules such as leptin and TNF- $\alpha$, collectively termed adipokines, that could affect vascular function by their local and distant actions.

Recent reviews have addressed the effect on endothelial function of the inter-related metabolic, biochemical and haematological factors associated with obesity (Williams et al. 2002; Yudkin, 2003). Abnormalities in LDL characteristics, increased activity of the rennin-angiotensin system and elevated concentrations of NEFA or TNF- $\alpha$ have all been implicated. However, the most compelling evidence is for an effect of inflammation, insulin resistance and/or elevated leptin concentration on the endothelium. The present review considers the role of insulin resistance, but focuses predominantly on the hormonal action of adipose tissue-derived secretions on vascular function.

\section{Insulin resistance and endothelial dysfunction}

A major unresolved issue in vascular biology is the nature of the link between insulin resistance states and endothelial function (Wheatcroft et al. 2003). The most accepted hypothesis is that insulin resistance leads to endothelial dysfunction. This hypothesis is supported by a close correlation between insulin sensitivity and both basal NO production in healthy volunteers and coronary artery endothelial function in subjects with cardiovascular risk factors but angiographically-normal coronary arteries. Treatment of insulin resistance with metformin improves endothelial function, which further supports this hypothesis. However, the results of studies using insulin-sensitising drugs (thiazolidinediones) are to date inconclusive.
An alternative hypothesis is that both insulin resistance and endothelial dysfunction have a common antecedent, possibly via inflammatory mediators released from adipose tissue (Yudkin, 2003) or even a common risk factor in the perinatal period. This common risk factor or "common soil' hypothesis, first put forward about 20 years ago, suggests that CVD and non-insulin-dependent diabetes mellitus share environmental and genetic antecedents (as if both conditions were 'springing from a common soil'; Stern, 1996). Fetal and early postnatal nutrition have been postulated to be the 'common soil' that programmes the development of the metabolic syndrome and so affects the propensity to both clinical CVD and non-insulin-dependent diabetes. The findings of programming of both insulin resistance and endothelial function by early growth acceleration, but no association between markers of insulin resistance and vascular health, suggest that early growth could be one common antecedent for the metabolic syndrome (Singhal \& Lucas, 2004).

Finally, a third hypothesis is that endothelial dysfunction induces insulin resistance (e.g. by reducing skeletal blood flow). However, it is unlikely that this mechanism is of major physiological importance. It also does not explain the association between low birth weight and both insulin resistance and endothelial dysfunction, but no correlation between these latter two factors (Singhal \& Lucas, 2004). Evidence of reduced muscle uptake of glucose but normal endothelial function in men with low birth weight also suggests that programming of insulin resistance can occur independently of an effect on endothelial function (Hermann et al. 2003). Thus, at least for programming effects, insulin resistance and endothelial dysfunction are not necessarily causally related.

\section{Leptin and endothelial function}

The concept that adipose tissue is not just a passive energy store but is highly physiologically active has become increasing important in understanding the role of obesity in vascular disease. Adipose tissue produces several biologically-active cytokine-like molecules that could directly affect blood vessels and hence could mediate the increased risk of CVD associated with obesity. Of these molecules the two most promising candidates for an effect on vascular function are leptin and adiponectin.

The primary role of the adipocyte-derived hormone leptin is in the regulation of appetite and body weight. Leptin concentrations rise exponentially with increasing percentage body fat, and obese individuals have markedly increased leptin production, probably as a consequence of resistance to its actions. However, the widespread distribution of functioning leptin receptors on vascular cells and other cell populations and on atherosclerotic lesions suggests that leptin also plays an important role in vascular physiology. In experimental models leptin has been shown to have angiogenic activity, to increase oxidative stress in endothelial cells and to promote vascular calcification and smooth muscle cell proliferation. The hypothesis that leptin is an important link between fat mass and the development of atherosclerosis is supported by findings in the ob/ob mouse, which lacks a functioning leptin gene and is 


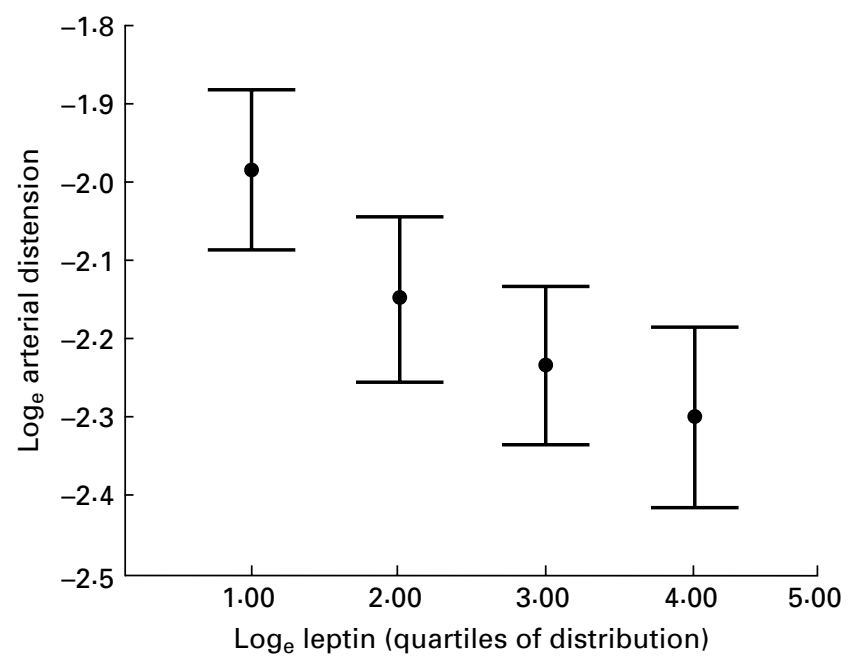

Fig. 2. Arterial distension according to quartiles of leptin distribution. Values are means and $95 \% \mathrm{Cl}$ represented by vertical bars. (Data from Singhal et al. 2002a.)

resistant to atherosclerosis despite being grossly obese (Nishina et al. 1994). Atherosclerosis risk in heterozygotes is intermediate between those of $o b / o b$ homozygotes and control animals, which suggests a dose-response relationship between leptin and the atherosclerotic process (Nishina et al. 1994). These mice also have delayed thrombus formation after arterial injury, a beneficial effect that is lost after leptin administration, probably as a consequence of leptin-mediated prothrombotic platelet activation (Konstantinides et al. 2001).

Consistent with these experimental studies and observations in animal models, an association has been shown between leptin and arterial distensibility that is independent of fat mass, inflammatory markers and insulin resistance (Singhal et al. 2002a; Fig. 2). These observations could be explained by the action of leptin, via receptors widely distributed on endothelial cells, to stimulate smooth muscle cell proliferation and migration, and hence impair arterial elasticity. Taken together with other evidence of adverse cardiovascular effects (Ren, 2004), including an increased risk of clinical CVD (Wallace et al. 2001), these findings suggest that a high leptin concentration is a key link between obesity and vascular disease. The fact that the findings relate to healthy non-obese adolescents further suggests that this link is important early in the atherosclerotic process.

\section{Adiponectin}

Adiponectin is unique amongst the adipocytokines in that increasing fatness is associated with a lower concentration. Adiponectin is suggested to have important anti-atherogenic and anti-diabetic properties and is found in lower concentrations in patients with insulin resistance, type 2 diabetes and CHD (Kumada et al. 2003). In vitro studies suggest that adiponectin might be cardio-protective by inhibiting TNF- $\alpha$-mediated monocyte adhesion, formation of foam cells and smooth muscle cell proliferation, and also by promoting blood vessel growth and endothelial NO production. In vivo, endothelial function is impaired in adiponectin knock-out mice, whereas forced adiponectin expression reduces atherosclerotic lesions in a mouse model of atherosclerosis.

Recently, hypoadiponectinaemia has been associated with impaired endothelial function in patients with mild hypertension and type 2 diabetes, and in healthy adult controls (Tan et al. 2004). However, there are relatively few data for man, especially for young individuals, that support an independent anti-atherogenic action of adiponectin. In contrast to previous reports, preliminary analyses suggest that hypoadiponectinaemia is associated with indices of insulin resistance but not with vascular function in healthy adolescents (A Singhal, unpublished results). These findings suggest that adiponectin contributes to the maintenance of insulin sensitivity in young, non-obese individuals but does not affect the development of early endothelial dysfunction.

\section{Conclusion}

The concept that atherosclerosis has its origins early in life is important for public health and the prevention of coronary artery disease. Both programming effects and conventional cardiovascular risk factors such as obesity in childhood have a major impact on the vascular biology of early atherosclerosis. Consequently, the increased risk of CVD with childhood obesity might be, in part, a consequence of the detrimental effect of adipose tissue on vascular health in general and on endothelial function in particular. This observation and the availability of potentially beneficial drugs such as statins and insulin-sensitising agents (Williams et al. 2002) point to the endothelium as a possible therapeutic target. Clearly, therefore, further research that aims to understand the interaction between adipose tissue and the vasculature, and so ultimately to reduce the cardiovascular complications of obesity, is now of the highest priority.

\section{References}

Anderson TJ, Uehata A, Gerhard MD, Meridith IT, Knab S, Delagrange D, Lieberman EH, Ganz P, Creager MA, Yeung AC \& Selwyn AP (1995) Close relation of endothelial function in the human coronary and peripheral circulations. Journal of the American College of Cardiology 26, 1235-1241.

Arcaro G, Zamboni M, Rossi L, Turcato E, Covi G, Armellini F, Bosello O \& Lechi A (1999) Body fat distribution predicts the degree of endothelial dysfunction in uncomplicated obesity. International Journal of Obesity and Related Metabolic Disorders 23, 936-942.

Barker DJP, Gluckman PD, Godfrey KM, Harding JE, Owen JA \& Robinson JS (1993) Fetal nutrition and cardiovascular disease in adult life. Lancet 341, 938-941.

Blacher J, Asmar R, Djane S, London GM \& Safar ME (1999) Aortic pulse wave velocity as a marker of cardiovascular risk in hypertensive patients. Hypertension 33, 1111-1117.

Brindle P, Emberson J, Lampe F, Walker M, Whincup P, Fahey T \& Ebrahim S (2003) Predictive accuracy of the Framingham coronary risk score in British men: prospective cohort study. British Medical Journal 327, 1267-1273. 
Brook RD, Bard RL, Glazewski L, Kehrer C, Bodary PF, Eitzman DL \& Rajagopalan S (2004) Effect of short-term weight loss on the metabolic syndrome and conduit vascular endothelial function in overweight adults. American Journal of Cardiology 93, 1012-1016.

Celermajer DS, Sorensen KE, Georgakopoulos D, Bull C, Thomas O, Robinson J \& Deanfield JE (1993) Cigarette smoking is associated with dose-related and potentially reversible impairment of endothelium-dependent dilation in healthy young adults. Circulation 88, 2149-2155.

Cheung YF, Wong KY, Lam BCC \& Tsoi NS (2004) Relation of arterial stiffness with gestational age and birth weight. Archives of Disease in Childhood 89, 217-221.

Cianfarani S, Germani D \& Branca F (1999) Low birthweight and adult insulin resistance: the 'catch-up growth' hypothesis. Archives of Disease in Childhood 81, F71-F73.

Clarkson P, Celermajer DS, Donald AE, Sampson M, Sorensen KE, Adams M, Yue DK, Betteridge J \& Deanfield JE (1996) Impaired vascular reactivity in insulin-dependent diabetes mellitus is related to disease duration and low density lipoprotein cholesterol levels. Journal of the American College of Cardiology 28, 573-579.

Frankel S, Elwood P, Sweetnam P, Yarnell J \& Davey Smith G (1996) Birthweight, body mass index in middle age and incident coronary heart disease. Lancet 348, 1478-1480.

Furchgott RF \& Zawadzki JV (1980) The obligatory role of endothelial cells in the relaxation of arterial smooth muscle by acetylcholine. Nature 288, 373-376.

Hahn P (1984) Effect of litter size on plasma cholesterol and insulin and some liver and adipose tissue enzymes in adult rodents. Journal of Nutrition 114, 1231-1234.

Hermann TS, Rask-Madsen C, Ihlemann N, Dominguez H, Jensen CB, Storgaard H, Vaag AA, Kober L \& Torp-Pedersen C (2003) Normal insulin-stimulated endothelial function and impaired insulin-stimulated muscle glucose uptake in young adults with low birth weight. Journal of Clinical Endocrinology and Metabolism 88, 1252-1257.

Hirai T, Sasayama S, Kawasaki T \& Shin-ichi Y (1989) Stiffness of systemic arteries in patients with myocardial infarction: a non-invasive method to predict severity of coronary atherosclerosis. Circulation 80, 78-86.

Klag MJ, Ford DE, Mead LA, He J, Whelton PK, Liang K \& Levine DM (1993) Serum cholesterol in young men and subsequent cardiovascular disease. New England Journal of Medicine 328, 313-318.

Konstantinides S, Schafer K, Koschnick S \& Loskutoff DJ (2001) Leptin-dependent platelet aggregation and arterial thrombosis suggests a mechanism for atherothrombotic disease in obesity. Journal of Clinical Investigation 108, 1533-1540.

Kumada M, Kihara S, Sumitsuji S, Kawamoto T, Matsumoto S, Ouchi $\mathrm{N}$ et al. (2003) Association of hypoadiponectinemia with coronary artery disease in men. Arteriosclerosis, Thrombosis and Vascular Biology 23, 85-89.

Kuvin JT \& Karas RH (2003) Clinical utility of endothelial function testing; ready for prime time? Circulation 107, 3243-3247.

Lamont D, Parker L, White M, Unwin N, Bennett SMA, Cohen M, Richardson D, Dickinson HO, Adamson A, Alberti KGMM \& Craft AW (2000) Risk of cardiovascular disease measured by carotid intima-media thickness at age 49-51: life course study. British Medical Journal 320, 273-278.

Leeson CPM, Kattenhorn M, Morley R, Lucas A \& Deanfield JE (2001) Impact of low birth weight and cardiovascular risk factors on endothelial function in early adult life. Circulation 103, 1264-1268.

Leeson CPM, Whincup PH, Cook DG, Donald AE, Papacosta O, Lucas A \& Deanfield JE (1997) Flow-mediated dilation in 9- to 11-year-old children. The influence of intrauterine and childhood factors. Circulation 96, 2233-2238.

Leeson CPM, Whincup PH, Cook DG, Mullen MJ, Donald AE, Seymour CA \& Deanfield JE (2000) Cholesterol and arterial distensibility in the first decade of life: a population-based study. Circulation 101, 1533-1538.

Lehmann ED, Riley WA, Clarkson P \& Gosling RG (1997) Noninvasive assessment of cardiovascular disease in diabetes. Lancet 350, Suppl. 1, 14-19.

Lewis DS, Bertrand HA, McMahan CA, McGill HC, Carey KD \& Masoro EJ (1986) Preweaning food intake influences the adiposity of young adult baboons. Journal of Clinical Investigation 78, 899-905.

Lewis DS, Mott GE, McMahan CA, Masoro EJ, Carey KD \& McGill HC (1988) Deferred effects of preweaning diet on atherosclerosis in adolescent baboons. Arteriosclerosis 8, 274-280.

Lloyd-Jones DM, Larson MG, Beiser A \& Levy D (1999) Lifetime risk of developing coronary heart disease. Lancet 353, 89-92.

Lucas A (1991) Programming by early nutrition in man. In The Childhood Environment and Adult Disease. CIBA Foundation Symposium no. 156, pp. 38-55 [GR Bock and J Whelan, editors]. Chichester, West Sussex: Wiley.

McAllister AS, Atkinson AB, Johnston GD \& McCance DR (1999) Relationship of endothelial function to birth weight in humans. Diabetes Care 22, 2061-2066.

McCance RA (1962) Food, growth and time. Lancet ii, 671-676.

Martin H, Hu J, Gennser G \& Norman M (2000) Impaired endothelial function and increased carotid stiffness in 9 year old children with low birthweight. Circulation 102, 2739-2744.

Martyn CN, Gale CR, Jespersen S \& Sherriff SB (1998) Impaired fetal growth and atherosclerosis of carotid and peripheral arteries. Lancet 352, 173-178.

Mullen MJ, Thorne SA \& Deanfield JE (1997) Non-invasive assessment of endothelial function. Heart 4, 297-298.

Must A, Jacques PF, Dallal GE, Bajema CJ \& Dietz WH (1992) Long-term morbidity and mortality of overweight adolescents: a follow-up of the Harvard Growth Study of 1922 to 1935. New England Journal of Medicine 327, 1350-1355.

Nishina PM, Naggert JK, Verstuyft J \& Paigen B (1994) Atherosclerosis in genetically obese mice: the mutants obese, diabetes, fat, tubby and lethal yellow. Metabolism 43, 554-558.

Norman M \& Martin H (2003) Preterm birth attenuates association between low birth weight and endothelial dysfunction. Circulation 108, 996-1001.

Palmer RMJ, Ferrige AG \& Moncada S (1987) Nitric oxide release accounts for the biological activity of endotheliumderived relaxing factor. Nature 327, 524-526.

Parker C, Vita JA \& Freedam JE (2001) Soluble adhesion molecules and unstable coronary artery disease. Atherosclerosis 156, 417-424.

Ren J (2004) Leptin and hyperleptinemia - from friend to foe for cardiovascular function. Journal of Endocrinology 181, 1-10.

Resnick LM, Militianu D, Cunnings AJ, Pipe JG, Evelhoch JL \& Soulen RL (1997) Direct magnetic resonance determination of aortic distensibility in essential hypertension: relation to age, abdominal visceral fat, and in situ intracellular free magnesium. Hypertension 30, 654-659.

Ross R (1993) The pathogenesis of atherosclerosis: a perspective for the 1990s. Nature 362, 801-809.

Shaper AG, Pocock SJ, Phillips AN \& Walker M (1986) Identifying men at high risk of heart attacks: strategy for use in general practice. British Medical Journal 293, 474-479.

Singhal A, Cole TJ, Fewtrell M, Deanfield J \& Lucas A (2004a) Is slower early growth beneficial for long-term cardiovascular health. Circulation 109, 1108-1113. 
Singhal A, Cole TJ, Fewtrell M \& Lucas A (2004b) Breastmilk feeding and lipoprotein profile in adolescents born preterm: follow-up of a prospective randomised study. Lancet 363, 1571-1578.

Singhal A, Cole TJ \& Lucas A (2001a) Early nutrition in preterm infants and later blood pressure: two cohorts after randomised trials. Lancet 357, 413-419.

Singhal A, Farooqi, Cole TJ, O'Rahilly S, Fewtrell M, Kattenhorn M, Lucas A \& Deanfield J (2002a) Influence of leptin on arterial distensibility; a novel link between obesity and cardiovascular disease. Circulation 106, 1919-1924.

Singhal A, Fewtrell M, Cole TJ \& Lucas A (2003) Low nutrient intake and early growth for later insulin resistance in adolescents born preterm. Lancet 361, 1089-1097.

Singhal A, Kattenhorn M, Cole TJ, Deanfield J \& Lucas A (2001 b) Preterm birth, vascular function and risk factors for atherosclerosis. Lancet 358, 1159-1160.

Singhal A, Lanigan J \& Lucas A (2002b) Early origins of obesity. In Obesity in Childhood and Adolescence. Nutrition Workshop Series, pp. 83-97 [C Hen and WH Dietz, editors]. Philadelphia, PA: Williams \& Wilkins.

Singhal A \& Lucas A (2004) Early origins of cardiovascular disease; is there a unifying hypothesis. Lancet 363, 1642-1645.

Singhal A, Sadaf Farooqi I, O'Rahilly S, Cole TJ, Fewtrell MS \& Lucas A (2002c) Early nutrition and leptin concentrations in later life. American Journal of Clinical Nutrition 75, 993-999.

Sorensen KE, Celermajer DS, Spiegelhalter DJ, Georgokopoulos D, Robinson J, Thomas O \& Deanfield JE (1995) Non-invasive measurement of human endothelium dependent arterial responses: accuracy and reproducibility. British Heart Journal 74, 247-253.

Spalding DA (1954) Instinct with original observations on young animals. British Journal Of Animal Behaviour 2, 2-11.

Stary HC (1989) Evolution and progression of atherosclerotic lesions in coronary arteries in children and young adults. Arteriosclerosis 9, Suppl. 1, I-19-I-32.

Steinberg HO, Chaker H, Leaming R, Johnson A, Brechtel G \& Baron AD (1996) Obesity/insulin resistance is associated with endothelial dysfunction. Implications for the syndrome of insulin resistance. Journal of Clinical Investigation 97, 2601-2610.

Stern MP (1996) Do non-insulin-dependent diabetes mellitus and cardiovascular disease share common antecedents? Annals of Internal Medicine 124, 110-116.

Stettler N, Zemel BS, Kumanyika S \& Stallings VA (2002) Infant weight gain and childhood overweight status in a multicenter, cohort study. Pediatrics 109, 194-199.
Tan KCB, Xu A, Chow WS, Lam MCW, Ai VHG, Tam SCF \& Lam KSL (2004) Hypoadiponectinemia is associated with impaired endothelium-dependent vasodilation. Journal of Clinical Endocrinology and Metabolism 89, 765-769.

Tounian P, Aggoun Y, Dubern B, Varille V, Guy-Grand B, Sidi D \& Girardet JP (2001) Presence of increased stiffness of the common carotid artery and endothelial dysfunction in severely obese children: a prospective study. Lancet 358, 1400-1404.

Vanhala M, Vanhala P, Kumpusalo E, Halonen P \& Takala J (1998) Relation between obesity from childhood to adulthood and the metabolic syndrome: population based study. British Medical Journal 317, 319.

Wallace AM, McMahon AD, Packard CJ, Kelly A, Shepherd J, Gaw A \& Sattar N (2001) Plasma leptin and the risk of cardiovascular disease in the west of Scotland Coronary Prevention Study (WOSCOPS). Circulation 104, 3052-3056.

Westerbacka J, Vehkavaara S, Bergholm R, Wilkinson I, Cockcroft J \& Yki-Jarvinen H (1999) Marked resistance of the ability of insulin to decrease arterial stiffness characterizes human obesity. Diabetes 48, 821-827.

Wheatcroft SB, Williams IL, Shah AM \& Kearney MT (2003) Pathophysiological implications of insulin resistance on vascular endothelial function. Diabetes Medicine 20, 255-268.

Wildman RP, Mackey RH, Bostom A, Thompson T \& SuttonTyrrell K (2003) Measures of obesity are associated with vascular stiffness in young and older adults. Hypertension $\mathbf{4 2}$, 468-473.

Wilkinson IB, Qasem A, McEniery CM, Webb DJ, Avolio AP \& Cockcroft JR (2002) Nitric oxide regulates local arterial distensibility in vivo. Circulation 105, 213-217.

Williams IL, Wheatcroft SB, Shah AM \& Kearney MT (2002) Obesity, atherosclerosis and the vascular endothelium: mechanisms of reduced nitric oxide bioavailability in obese humans. International Journal of Obesity 26, 754-764.

Yamashita T, Sasahara T, Pomeroy SE, Collier G \& Nestel PJ (1998) Arterial compliance, blood pressure, plasma leptin, and plasma lipids in women are improved with weight reduction equally with a meat-based diet and a plant-based diet. Metabolism 47, 1308-1314.

Yudkin JS (2003) Adipose tissue, insulin action and vascular disease: inflammatory signals. International Journal of Obesity 27, S25-S28.

Ziccardi P, Nappo F, Giugliano G, Esposito K, Marfella R, Cioffi M, D'Andrea F, Molinari AM \& Giugliano D (2002) Reduction of inflammatory cytokine concentrations and improvement of endothelial functions in obese women after weight loss over one year. Circulation 105, 804-809. 